\title{
Seller Reviews and Consumers' Perceptions of Trust, Risks, and Uncertainty
}

\author{
Jing Yang, SUNY Oneonta, Oneonta, USA \\ Rathindra Sarathy, Oklahoma State University, Stillwater, USA \\ (iD) https://orcid.org/0000-0001-7352-2676 \\ Tao Wu, SUNY Oneonta, Oneonta, USA
}

\begin{abstract}
Based on the principal-agent theory, the authors posit that seller-related uncertainty is derived from buyer (the principal) fears of hidden information (information asymmetry) and hidden action (seller opportunism) on the part of sellers (the agents). The study evaluates the effects of the three antecedents of trust in the seller reviews context with a quasi-experiment. The authors enhance the validity of the research manipulation through a unique approach of creating reviews through a text mining process of actual seller reviews. This allows control over the content of reviews while retaining their realism. The findings validate that the principal-agent theory provides a good fit for understanding seller-related uncertainty in e-commerce transactions. Second, buyers appear to be more concerned about seller opportunism than with information asymmetry. Third, while assessments of integrity and competence of the vendor, assessed through reviews, play a role, benevolence does not.
\end{abstract}

\section{KEYWORDS}

Perceived Information Asymmetry, Perceived Seller Opportunism, Perceived Uncertainty, Seller Reviews, Trust

\section{INTRODUCTION}

Electronic commerce (e-commerce) has unquestionably become an indispensable part of our lives. However, effectively eliminating the in-built risks and uncertainty in e-commerce remains a challenge to many businesses. In general, customer reviews are provided to strengthen information transparency about products/services and mitigate related risks and uncertainty during a purchasing process. Many researchers already noticed the effect of customer reviews in this regard; however, the majority of the discussions so far are primarily centered on the characteristics related to either reviews themselves or the products under scrutiny (or both). For example, substantial studies found that the characteristics of reviews such as average ratings (Jiang \& Wang, 2008), dispersion of ratings (Zhu \& Zhang, 2010), review valence (Clemons, Gao, \& Hitt, 2006), review quantity (Chevalier \& Mayzlin, 2006), etc. play a role in consumers' decision making. These factors have been, with varying degrees of success, shown to play a role in product sales growth, price premium and so on. Other factors, which have also been mentioned, are more related to products themselves, such as product quality (Jiang \& Wang, 2008), product price (Ghose \& Ipeirotis, 2010), product age (Hu, Liu, \& Zhang, 2008), product popularity (Zhu \& Zhang, 2010). 
Beyond this, there is another stream of research which is focused more on semantic patterns embedded within customer reviews. For example, Ong et al. state that shill reviews (fake or manipulated reviews) created to manipulate the reputation of products are prone to have more official features per sentence, a higher percentage of sentences containing official features, and less readability (Ong, Mannino, \& Gregg, 2014). Tian et al. demonstrate a refined classification scheme to deal with sentiments expressed in product reviews (Tian et al., 2016). Ahmad and Laroche found that the emotions expressed in reviews may influence people's perception of the helpfulness of such reviews (Ahmad \& Laroche, 2015). For example, the hope expressed in the reviews may have a negative effect, and happiness may have a positive effect.

In this study, we are specifically interested in the emotions that are revealed in the comments of seller reviews, which are technically more related to the performance of sellers (seller reviews as opposed to product reviews) and their associated impact on prospective buyers' trust. Many studies show trust can be transferred from one entity to another; and this sort of trust transference is viewed as one of the effective strategies to develop trust (Lim, Sia, Lee, \& Benbasat, 2006). That is, when a consumer trusts a popular web portal such as eBay or Amazon, he will tend to trust sellers affiliated with the portal based solely on the reputation of that web portal (Lim et al., 2006). Cheung and Lee validated this positive relationship between trust belief and purchase intention (Cheung \& Lee, 2008). Pavlou and Dimoka find a similar positive correlation between trust and price premium (Pavlou \& Dimoka, 2006). On these grounds, we assume that if a consumer trusts a seller, he/she will trust this seller's products as well. Consequently, we believe that the trust feeling expressed in seller reviews can influence consumers' impressions about their products. This premise provides the rationale for our study.

In addition, we want to further measure that in what conditions prospective buyers' trust perceptions will be influenced by seller reviews. As addressed earlier, plenty of studies find that the content of reviews has a certain ability to influence people's perceptions and consequently their purchase behavior. However, not many of them try to explore it from an angle of trust. In this regard, we integrate a quasi-experiment with a content analysis, because understanding the role of semantics in seller reviews requires that we are able to manipulate semantic patterns in a structured fashion in an experimental or quasi-experimental setting. In reality, seller reviews contain a variety of information, not all of which may be related to trust in sellers. Consistent with the focus of our study and following ideas from semantics-based studies, we perform content analysis on actual seller reviews to uncover semantic patterns related to trust in sellers and subsequently create seller reviews with particular characteristics to understand their impact on trust-related characteristics.

Beyond this, we continue to measure the effects of seller reviews on other perceptions such as potential risks and uncertainty. Principal Agent Theory is used in this regard. As instructed in the theory, we measure prospective consumers' concerns on sellers' potential hidden actions and hidden information. We posit that seller-related uncertainty is derived from buyers' (the principal's) fears of hidden information (information asymmetry) and hidden actions (seller opportunism) on the part of sellers (the agents). Buyers use the information in seller reviews to assess the possibility of hidden information and hidden actions. Following the findings in the content analysis, several reviews are used in a quasi-experimental setting to manipulate the feelings related to trust by using specific combinations of three antecedents of trust to test a theory-based model, where treatment manipulation is present but not randomization. Surveys are used for data collection purpose.

Our study contributes to the extant literature from the following perspectives. First, our findings validate that the principal-agent theory provides a good fit for understanding seller-related uncertainty in e-commerce transactions. Second, our study shows that prospective buyers appear to be more concerned about seller opportunism rather than with information asymmetry. Third, while assessments of integrity and competence of the vendor, assessed through reviews, play a role, benevolence does not.

The rest of the paper is organized as follows. In Section 2, the theoretical background underlying the study is introduced, including both the theory and the methodology adopted. Section 3 discusses 
the content analysis to uncover semantic patterns in actual seller reviews with an emphasis on trust. Section 4 describes the survey and the quasi-experimental design. In Section 5, the detailed analyses of hypothesis test and model establishment are presented. The paper ends with a discussion of the findings and potential future work.

\section{THEORETICAL BACKGROUND AND HYPOTHESES}

This study is founded on two theories - trust and the principal-agent theory. The trust theory provides the foundation for the understanding of consumers' information processing of the content of seller reviews. The principal-agent theory provides a means to measure consumers' psychological processing of those semantic cues in seller reviews.

\section{Trust in E-commerce}

Trust is a central concept in e-commerce transactions (Awad \& Ragowsky, 2008; Kim, Ferrin, \& Rao, 2008; Lim, et al., 2006). Wang et al. point out that online users' cognition-based trust (derived from expectations and beliefs, etc.) and affect-based trust can enhance their perception of a recommendation agent' usefulness and enjoyment with the presence of rational appeals (represented by explanation facilities) and social appeals (represented by avatar interface) (Wang, Qiu, Kim, \& Benbasat, 2016). Their empirical test results indicate that these two types of trust are capable of explaining $56 \%$ of the variation in users' perceived usefulness and $41 \%$ of the variation in their perceived enjoyment. In the context of online payment, Rouibah et al. tested the effect of perceived enjoyment and perceived risk on trust formation and intention to use (Rouibah, Lowry, \& Hwang, 2016). Their study indicates that, in the Arabic context, users' intention to adopt an online payment tool is influenced by their personal innovation, propensity to trust, and familiarity with the tool which are further mediated by three beliefs including perceived enjoyment, trust and perceived risk, among which their trust in the tool can interpret $17.6 \%$ of the variation in the adoption intentions.

It is commonly understood that trust can be altered by a person's encounter with a stimulus such as a third-party seal on a website or even the perceived quality of that website. For example, Kim et al. find that the presence of a third-party seal provided by third-party certificating bodies such as banks, consumer unions or computer companies, can enhance consumers' trust of online retailers (Kim et al., 2008). Gefen et al. note that consumers' knowledge-based familiarity and perceived ease of use of a website have a positive influence on their trust in the e-vendors (Gefen, Karahanna, \& Straub, 2003). So, it is obvious that although a trust belief is an internal feeling, it is possible to be influenced by the cues embedded in the source of information and may eventually impact consumers' attitudes toward behavior such as purchase intention, etc. This type of trust is also called cue-based trust (Sparks, Perkins, \& Buckley, 2013).

In the context of online reviews, the significance of trust beliefs has already been noted. For instance, Utz et al. compared the efficacy of consumer reviews, online stores reputation, and assurance seals (delivered by trusted third parties) on the formation of consumers' trust in those online stores (Utz, Kerkhof, \& van den Bos, 2012). Their findings indicate that consumer reviews play a comparatively more important role in the judgment of an online store' trustworthiness than other two factors; especially, the positiveness of reviews would reinforce consumers' perceived trustworthiness of those online stores. With a focus on tourism product purchase, Sparks et al. show that consumers' beliefs (such as the utility of reviews, trust, and quality of service) resulting from information cues provided in reviews are more favorable for consumer-generated content than for manager-generated content (Sparks, et al., 2013). In particular, consumer-written reviews with specific comments on the performance of the service would be considered more trustworthy and thus result in a stronger purchase intention.

In our case, the arguments in seller reviews can be regarded as information cues. Following the logic above, we believe that seller reviews also have the ability to alter consumers' beliefs, especially 
trust belief. However, how this effect works is still a question to consider. As such, we adopted the three traditional antecedents to measure the trust belief involved in seller reviews - benevolence, competence, and integrity. In our context, benevolence measures the extent to which a seller cares about the preferences of a buyer (Fang, Guo, \& Zhang, 2015), that is, the willingness of the seller to behave well for the sake of the buyer. Integrity measures the extent to which a seller conforms to a norm or code of moral in business (Fang et al., 2015); that is, the buyer believes that the seller will always keep good-faith agreements, tell the truths, act ethically and fulfill his/her promises to the buyer. Competence measures the ability of a seller to conduct the actions that are expected by a buyer in an online transaction (Fang, et al., 2015); for example, if the seller promises to ship a product within 2 days, the buyer believes that he/she has such an ability to keep the promise. These three antecedents comprehensively measure the cognitive process of interpersonal trust in e-commerce. Therefore, we adopt them as a basis for the rest of the study and contribute by measuring these three antecedents respectively rather than a single construct as other studies do (Awad \& Ragowsky, 2008; Gefen, et al., 2003), to achieve a deeper understanding of the cognitive process.

\section{Risks and Uncertainty}

The second factor of interest is consumers' cognitive processing of the information embedded in reviews. The psychometric factors chosen here are risks and uncertainty for a simple reason - online reviews were initially invented for the purpose of mitigating future consumers' perceived risk and uncertainty. As such, we decided to test the efficacy of seller reviews on these two perceptions aligning with the principal-agent theory. The theory deals with a principal-agent dilemma with possible risks and uncertainty originating from hidden information and hidden actions. In theory, it is assumed that principals hire agents to pursue their interests. For example, stockholders hire a CEO to operate a company. The stockholders in the case are the principals, and the CEO is the agent. The agent acts on behalf of the principals; however, both of them are assumed self-interested economic entities, which means that agents may undertake some acts to achieve their interests while sacrificing principals' interests. The theory indicates that the temporal separation between the goal integrity and principals and agents causes the existence of hidden information and hidden actions in the principal-agent relationship which causes risks and produces uncertainty eventually (Bergen, Dutta, \& Walker, 1992; Mishra, Heide, \& Cort, 1998; Pavlou, Huigang, \& Yajiong, 2007; Singh \& Sirdeshmukh, 2000).

The principal-agent theory has also been extended by some researchers into the field of e-commerce to explain the buyer-seller relationship (Pavlou et al., 2007). In the context of e-commerce, sellers can be considered as the agents and buyers can be considered as the principals. The orders placed online can be considered as the contracts between sellers and buyers. Before buyers physically receive their products, sellers still have opportunities to harm the benefits of buyers. Therefore, there exist similar problems of hidden information and hidden actions due to this spatial and temporal separation between sellers and buyers, because sellers theoretically have more knowledge of product quality and the way how related transactions will be executed than buyers do. The associated uncertainty consequently will prevent buyers from buying from sellers. Here the hidden information refers to the occasions when sellers intentionally hide information about the products and transactions, and the hidden actions refer to the occasions when sellers break their promise by sending low quality or counterfeit products to consumers (Pavlou et al., 2007).

There is evidence that the principal-agent theory can explain the relationship between risks and uncertainty in e-commerce very well. For example, using this theory, Pavlou et al. (2007) uncovered significant effects of four potential risks in online transactions, including perceived information asymmetry, fears of seller opportunism, information privacy concerns and information security concerns, on the formation of consumers' perceived risk in e-commerce (Pavlou et al., 2007). Perceived information asymmetry is more related to the risk of hidden information, since both result from the asymmetrical distribution of information between buyers and sellers. The fears of seller opportunism correspond to the risk of hidden actions resulting from activities such as quality cheating, contract 
default, and failure to acknowledge return or refund and so on. Information privacy concerns and information security concerns are more relevant to the risks related to the environment of websites (Pavlou et al., 2007).

Indeed, the risks in e-commerce can be measured in other ways. For instance, some researchers prefer to measure an overall risk by asking the subjects directly the extent to which they would think the transaction is risky, is likely to cause trouble in the future or is associated with a good chance of mistakes they would make (Laroche, Yang, et al., 2005) and so on. On the other hand, some researchers would like to conduct a deeper examination of the sources of risks in e-commerce. For example, some researchers measured risks as financial risks, time risks, performance risks and social risks (Laroche et al., 2005; Laroche \& Nepomuceno, 2010). It is obvious that the measurement of risks in e-commerce can vary as conditions change.

In this study, we adopted the idea from the Pavlou et al. (2007) study for two reasons. First, the theoretical framework proposed in their study is more consistent with the principal-agent theory, especially the part related to risks and uncertainty. Secondly, in addition to the risks, they also examined the impact of other factors such as product diagnosticity, website informativeness, trust and social presence of a web portal, in the context of online book purchasing and prescription filling, on the formation of consumers' purchase intention (Pavlou et al., 2007). Although in their study the trust was measured as a single construct, the findings of their study provide us a solid foundation for our study, which suggests a reasonable hypothesis on the relationship between the trust and the risks in e-commerce. However, privacy and security concerns, while important and interesting, are not relevant to our focal questions. Therefore, we removed them from our study and simply adopted the instruments in Pavlou et al.'s study to measure perceived information asymmetry and fears of seller opportunism. As indicated in that study, buyers will perceive less information asymmetry and will have a lower fear of seller opportunism, when transacting with vendors they trust. Hence, we hypothesize as follows:

Hypothesis One: Perceived benevolence has a negative effect on perceived information asymmetry. Hypothesis Two: Perceived benevolence has a negative effect on fears of seller opportunism.

Hypothesis Three: Perceived competence has a negative effect on perceived information asymmetry. Hypothesis Four: Perceived competence has a negative effect on fears of seller opportunism.

Hypothesis Five: Perceived integrity has a negative effect on perceived information asymmetry. Hypothesis Six: Perceived integrity has a negative effect on fears of seller opportunism.

Uncertainty is another common factor to consider in e-commerce. For instance, Gregg and Walczak claim that increasing the quality of the e-images on websites can help reduce both the uncertainty and perceived risks in online transactions (Gregg \&Walczak, 2008) as does information vividness (Weathers, Sharma, et al. 2007). In the context of consumer reviews, a similar effect has also been mentioned. For example, Weathers et al. note that reviews written by third parties are more effective at reducing uncertainty and enhancing information credibility with regard to search products, and product reviews provided by retailers are more effective at lowering uncertainty regarding experience products (Weathers, Sharma, et al. 2007). Here products such as MP3 players, music CDs, and PC video games, are viewed as experience products, and products such as cell phones, digital cameras, and Laser printers, are viewed as search products (Mudambi \& Schuff, 2010). Compared to experience products, which are typically rated subjectively, the quality of search products is easier to evaluate objectively. There is also evidence illustrating that trust can help mitigate the perceived uncertainty in e-commerce. For instance, Gefen's study indicates that consumers' knowledge-based familiarity of a shopping website and associated trust can ease their worries on potential uncertainty towards the transactions and simplify their buyer-seller relationship (Gefen, 2000). Kim et al. also find that consumers' trust has the ability to relieve their worries on potential risks and consequently foster the formation of purchase intent (Kim, Ferrin et al., 2008). Pavlou et al. (2007) hypothesized 
that because the buyer has to make decisions based on limited information (such as found in the seller reviews) in dealing with risks of hidden information and seller opportunism. Consistent with the Pavlou et al. (2007) study we hypothesize that the effect of trust on perceived uncertainty is mediated by perceived risks in the form of hidden information and seller opportunism.

Hypothesis Seven: Perceived information asymmetry has a positive impact on perceived uncertainty. Hypothesis Eight: Fears of seller opportunism has a positive impact on perceived uncertainty.

Figure 1 shows our research model. Briefly, the model indicates that consumer reviews on sellers influence their trust belief. Trust belief is expressed in its antecedents: benevolence, competence, and integrity. The model is built on the proposition that consumers use reviews to reduce the risk and uncertainty inherent in e-commerce transactions. Based on the principal-agent theory, sellers can be treated as agents and buyers as principals, and the online transaction is viewed as a contract between the purchaser and the seller. Agents represent principals, but each is assumed to act in his or her own interests as well. Sellers are assumed to know more than the buyers about the quality of products. Two specific risks undertaken by the purchasers (principals) are hidden information (information asymmetry) and hidden action (seller opportunism) on the part of the agents. This is assumed to create uncertainty in online transactions. Hence, buyers use seller reviews as a basis for their trust in sellers, in turn making judgments on the risks of hidden information and hidden actions, thereby reducing the uncertainty of the online transactions.

\section{SEMANTIC PATTERN UNCOVERING RELATED TO TRUST}

\section{Data Preparation}

In order to manipulate trust in our study, our first step is to uncover the semantic patterns related to the trust belief embedded in seller reviews using a simple text mining tool. Specifically, we are interested in examining how much information related to trust belief in sellers is incorporated in seller reviews and what words are used to express this trust belief. All the seller reviews were real

Figure 1. Research model for the impact of seller reviews on uncertainty in e-commerce transactions

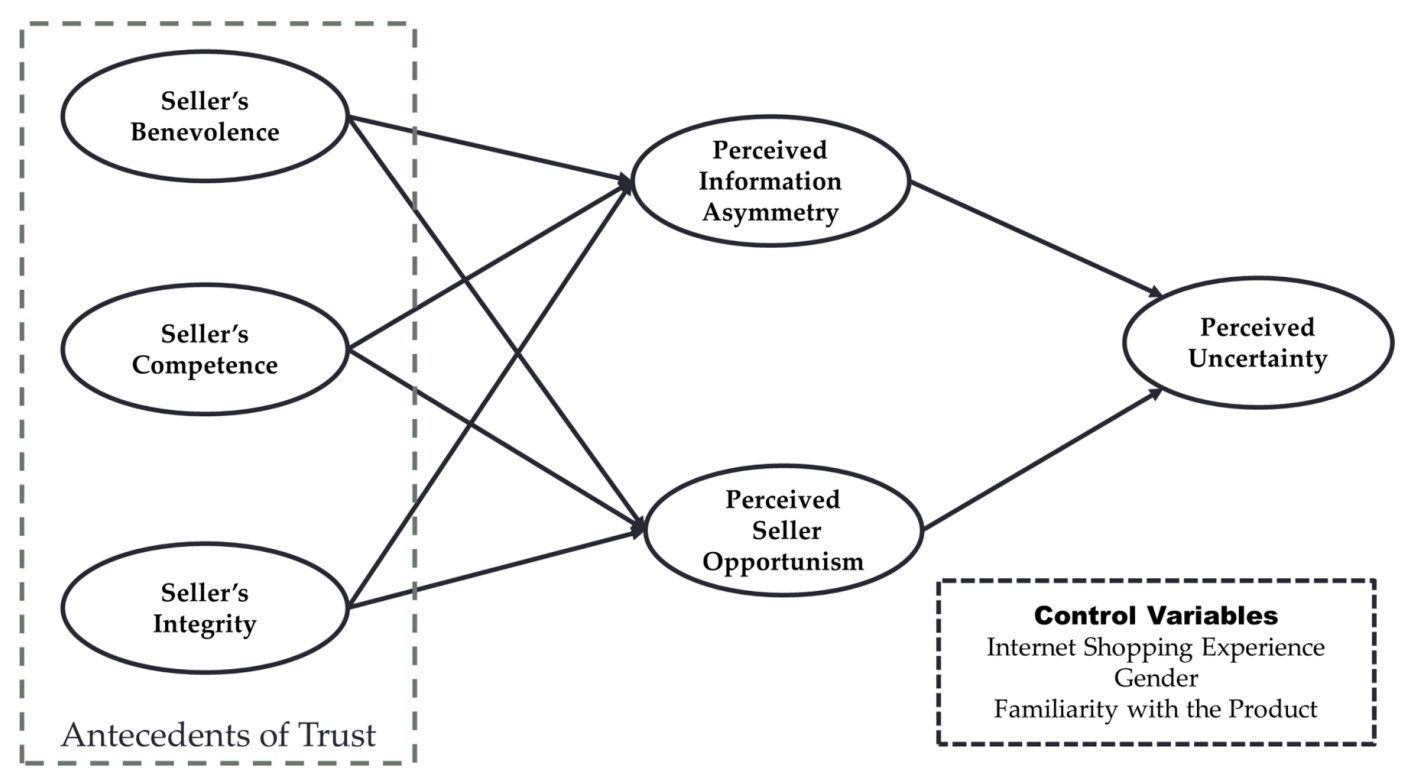


and collected from ebay.com. The format of reviews on eBay varies slightly from other portals. First, the length of reviews is specified. Other web portals, such as Amazon, grant consumers flexibility in the length of their reviews. In contrast, eBay only allows consumers 80 characters for each review; this is beneficial to our study because the opinions are condensed and expressed in an efficient way. eBay reviews differ in a second way: the reviews are anchored on a 3-point scaling system-positive, neutral, and negative. Normally, reviews are measured on a 5-point scale-extremely dislike, dislike, neutral, like, and extremely like. eBay's 3-point scale is preferable for our study because it lessens the complexity of review content. Therefore, the reviews from eBay are the best for our study.

To increase the generality of reviews, we intentionally collected the reviews from different sellers. The merchandise these sellers sell includes shoes, clothes, CDs, collectibles, and small furniture. To avoid the one-sidedness caused by the unique performance of one specific seller, we collected only ten most recent reviews from fifty vendors in July 2015. In the end, we amassed 500 reviews in each of the three categories of reviews - positive, neutral, and negative. With the focus of this study on sellers and not products, 500 reviews in each category reveal sufficient information about sellers' performance in transactions.

To generate wordlists, we follow a general procedure in text mining consisting of the following principal steps: 1) tokenizing; 2) removing stop words; and 3) stemming (Delen \& Crossland, 2008; Weiss, 2005). Tokenization is the most critical step as it converts unstructured textual documents into numerical vectors. After tokenizing the text, all words are assigned a number to represent the frequency of that word appearing in the document. A certain number of words, including articles, prepositions, conjunctions and some other high-frequency words such as a, the, of, and, I, it and you, do not have real meaning (Zhan, Loh, \& Liu, 2009). Removing stop words is a required step to shorten the list of words in the vector. Another necessary step to shorten the wordlist is stemming. Some words-deriving from the same root word-have different formats and are counted separately by software. Semantically, these words (for example, carry, carrying, and carried) simply represent duplicated information. Stemming looks for the word deriving from the same root and keeps only the root word in the word list. These are only three basic steps in document processing. More steps can be added into the analytical pipelines as needed.

The procedure above was applied to all documents with positive, neutral, and negative reviews respectively. In general, the procedure of implementing text mining is standardized regardless of star ratings. All the reviews manually copied from eBay and pasted into Excel spreadsheets. To facilitate the subsequent analysis, we created three spreadsheets respectively for each type of reviews. The software used for text mining is Rapidminer 5. Compared to other data-mining software, Rapidminer was selected for its friendly interface, free license, and free plugins such as text mining, Weka, Web Mining and so on. Rapidminer enables users to create analytic pipelines, which also allow us to standardize the analytic procedures for all documents regardless of star ratings. The analytic pipeline involves 1) reading the documents from Excel spreadsheets; 2) converting data into documents in Rapidminer; 3) converting the documents into numerical data; 4) generate the word list in the documents, and 5) export the outputs into Excel tables.

The procedure for processing the document follows common steps in the literature (Delen \& Crossland, 2008; Weiss, 2005; Zhan, et al., 2009). It uses the following steps: 1) transform all words into lowercase; 2) tokenize words in the documents using an English dictionary; 3) filter (remove) stopwords using an English dictionary; 4) filter the words with the frequency of less than 3, which means if the word did not appear in all the documents more than 3 times, it would be excluded from the wordlist; 5) stem the words based on the Porter algorithm; 6) generate the terms with a maximum of 3 words, which means the phrases with more than 3 words would be excluded from the wordlist ; 7) report the number of tokens and the length of the document in the output. Specifically, in step 5, the Porter stemming algorithm, also called the suffix stripping algorithm, is a set of pre-stored rules to remove the suffixes such as 'ed', 'ing', and 'ly' from the derived words to get their root form (Porter, 1980; Zhan et al., 2009). 
After processing the document, three lists of words were produced respectively for positive, neutral, and negative reviews. We then eliminated obvious synonyms, for example, the words such as 'eBayer' and 'seller' or 'ship' and 'deliver.' Some reviewers prefer to say 'Good eBayer' instead of 'Good seller,' but obviously, the eBayer in the review refers to the seller in the transaction. Sometimes reviews say 'fast delivery' instead of 'fast shipping.' For this study, the word 'delivery' is considered equivalent to 'shipping.' In some reviews, reviewers specify the name of the products they have bought, and product type is not our concern. Therefore, all the product names appearing in reviews, such as 'phone' or 'shoe,' were uniformly converted to 'product.' Another type of transformation is to break duplicated phrases down into their root terms. Since terms with no more than three words are allowed, some phrases in the wordlists just represent the duplicated information as their root words do. For example, 'fast_ship_thank' literally means 'fast shipping' and 'thank you,' which have already been included in the wordlist, so there is no reason to keep them in the wordlists.

\section{Major Findings in Text Mining}

Consistent with the common understanding, most of the positive reviews are compliments from prior consumers. The major ideas in positive reviews include:

- The seller is great

- The consumer thanks the seller

- The shipping was fast/quick

- The product/item is good/perfect and as advertised/described

In contrast to positive reviews, most of the comments in negative reviews are complaints from former consumers. The topics of negative reviews ranged from poor service to poor quality of the products. In summary, the main ideas in negative reviews include:

- The buyer did not receive the purchased item, and has been waiting for a while

- The item is bad/horrible

- The item sent was wrong or not as described/pictured

- The item was not refunded on time, and a high fee was charged for refunding

- The order got canceled due to a shortage of stock

- The seller was hard to communicate with, and/or the service was poor

Unlike either positive reviews or negative reviews, the emotion in neutral reviews is more complex. Overall, neutral reviews represent a negative attitude toward the transaction. However, this kind of dissatisfaction is accompanied by some degree of a positive attitude toward the transaction. Therefore, neutral reviews have both positive comments and negative comments as follows:

- $\quad$ The item was shipped quickly

- The item was shipped slowly and arrived later than expected

- The item was good/fine

- The item was not good and does not work

- The item was not as described/pictured and the buyer has to refund/return it

- The product looks cheap, and the quality of the product looks poor

\section{How do Reviews Reveal the Trust Feeling?}

As broadly discussed in the literature of trust, three antecedents-competence, benevolence, and integrity - shapes trust (McKnight \& Chervany, 2001). Competence emphasizes the belief that online sellers have the ability to accomplish what they promised; benevolence focuses on the belief that 
online sellers care about consumers' benefit and act in consumers' interest; integrity is the belief that an online seller will not take any opportunity to impair consumers' benefits (McKnight, Choudhury, \& Kacmar, 2002; Pavlou, et al., 2007). As discussed earlier, the main topics covered in seller reviews including 1) shipping, 2) overall assessment of sellers, 3) orders fulfillment, 4) after-sale service, 5) product return and 6) product quality and so on. Comparing these with the definition of the three antecedents of trust, we identified words reflecting sellers' attitudes, such as 'easy to communicate' or 'can never get in touch with the seller' as being related to sellers' benevolence; words reflecting sellers' ability to fulfill the purchasing agreement, such as 'arrived earlier than expectation' or 'well packed', are related to sellers' ability; and words such as 'item as described' or 'pre-owned: useless', are related to sellers' integrity. As such, the majority of the seller reviews can be theoretically classified based on the trust belief embedded in them, as illustrated in Table 1.

\section{SURVEY ADMINISTRATION}

\section{Experiment Design}

We conducted a survey to measure the impact of trust feeling on perceived uncertainty. The $2 \times 2 \times 2$ quasi-experiment is illustrated in Table 2. Eight versions of the online survey posted on Qualtrics. com were created. Qualtrics is a web-based survey software that enables users to develop and collect responses to surveys. The surveys were emailed to around 450 undergraduate students in the business school of a mid-western university in the US. All the instruments used in the study were adopted and adapted from previous research assessed on a five-point scale anchored at $1=$ strongly disagree, 3 $=$ neutral and $5=$ strongly agree (see Appendix 1).

In each survey, the subjects were requested to read four reviews of the same category as designed in Table 2. To control the effect of seller reviews and ensure that the reviews in the experiment function as intended, we constructed reviews based on the key words from text mining of real reviews as described earlier. As an example, shown in Table 3, we looked at three individual reviews and ensured that at least one aspect of trust is part of each review, and then combined these three reviews into a single review. In this way, we ensure that every review in the experiments embraces complete information of former consumers' trust. As a check, before the experiment, the sample reviews were presented to a small group of people with a good understanding of e-commerce. All of them could classify the type of reviews as designed.

\section{Data Collection}

392 responses were received in the survey. Several steps were necessary to clean up data: 1) Delete incomplete responses: 13 incomplete responses with less than $20 \%$ completion rate were deleted, leaving 379 responses. 2) Delete non-first-time responses: 20 non-first-time responses were deleted,

Table 1. Sample reviews related to trust

\begin{tabular}{|l|l|}
\hline \multicolumn{1}{|c|}{ Trust } & \multicolumn{1}{c|}{ Sample Reviews } \\
\hline Benevolence & $\begin{array}{l}\text { Tracking number provided isn't valid, can't get a response from seller. In limbo! } \\
\text { Item is defective. Under seller instr., returned for a refund. Refund never seen. } \\
\text { Seller shipped the item, but it never arrived, Got a full refund good communication }\end{array}$ \\
\hline Competence & $\begin{array}{l}\text { Very nice eBayer with fast transaction and nice items. } \\
\text { As described, well packed, fast shipping. Recommended!!! } \\
\text { Shipping was slow, the product was wrong, was not refunded full purchase price. }\end{array}$ \\
\hline Integrity & $\begin{array}{l}\text { Pre-owned: } \text { useless. misleading, never again! } \\
\text { Received a totally different case than the picture } \text { and the seller won't respond } \\
\text { Fast shipping, item as described! }\end{array}$ \\
\hline
\end{tabular}


Table 2. Seller reviews used in the study

\begin{tabular}{|l|l|}
\hline \multicolumn{1}{|c|}{ Review Version } & \multicolumn{1}{c|}{ Description } \\
\hline Version1 & Positive Benevolence + Positive Competence + Positive Integrity \\
\hline Version2 & Negative Benevolence + Positive Competence + Positive Integrity \\
\hline Version3 & Positive Benevolence + Negative Competence + Positive Integrity \\
\hline Version4 & Negative Benevolence + Negative Competence + Positive Integrity \\
\hline Version5 & Positive Benevolence + Positive Competence + Negative Integrity \\
\hline Version6 & Negative Benevolence + Positive Competence + Negative Integrity \\
\hline Version7 & Positive Benevolence + Negative Competence + Negative Integrity \\
\hline Version8 & Negative Benevolence + Negative Competence + Negative Integrity \\
\hline
\end{tabular}

Table 3. An example of seller reviews in the experiment

\begin{tabular}{|l|l|l|l|}
\hline \multicolumn{2}{|c|}{ Original reviews } & \multicolumn{2}{|c|}{ Manipulated review } \\
\hline Benevolence & $\begin{array}{l}\text { The item actually didn't work for me, } \\
\text { and I had to return it. The process for } \\
\text { returning was incredibly well designed - } \\
\text { It's how a company treats the consumer } \\
\text { when things DON'T go well that sets } \\
\text { them truly apart. Thank you! (PB) }\end{array}$ & $\rightarrow$ PB+PC+PI & $\begin{array}{l}\text { Arrived earlier than expected. Item } \\
\text { works as advertised, quick shipping, } \\
\text { and good packaging. However, the item } \\
\text { actually didn't work for me, and I had } \\
\text { to return it. The process for returning } \\
\text { was incredibly well designed - It's how } \\
\text { a company treats the consumer when } \\
\text { things DON'T go well that sets them } \\
\text { truly apart. Thank you! }\end{array}$ \\
\cline { 1 - 2 } Competence & $\begin{array}{l}\text { Arrived earlier than expected. Very } \\
\text { satisfied with the product. (PC) }\end{array}$ & $\begin{array}{l}\text { Item works as advertised, quick } \\
\text { shipping, and good packaging. (PI) }\end{array}$ & \\
\hline
\end{tabular}

with 359 responses remaining. This step was needed because the participants in the experiment were simultaneously recruited from several classes in a business school. To avoid duplicated responses, we intentionally asked a question at the end of each survey to check the uniqueness of that reply. 3) Delete the responses with strong evidence showing the participant's lack of attention on the survey: the participants were intentionally requested to choose "strongly agree" or "strongly disagree" on three questions to check that the participants at least carefully read the questions in the survey. 141 responses indicated a lack of attention to the survey questions and were deleted. After deleting responses in these three areas, 218 valid responses remain in the study. Table 4 illustrates the sample size for each version of the surveys.

\section{Demographics of the Participants}

Overall, the participants in our study were young and highly educated; however, considering the general characteristics of online shoppers who normally tend to be young, we would think our participants can not only represent the general behavior of normal online shoppers but also have a good ability to understand the information exposed in the experiment. As revealed in Table 5, 90.4\% of our participants have more than one online shopping experience in the past year, and $11 \%$ of them have more than 20 experiences in the past year. Therefore, we believe it is reasonable to assume that most of the participants have sufficient experience and ability to well understand the questions in the experiment.

In addition, ShopTronics is a real seller on eBay and all the product information being used in the experiment are real though the reviews have been manipulated in line with the experiment design and 
Table 4. Sample size for each survey

\begin{tabular}{|l|l|l|}
\hline \multicolumn{1}{|c|}{ Review Type } & \multicolumn{1}{|c|}{$\begin{array}{c}\text { Number of } \\
\text { Responses }\end{array}$} & \multicolumn{1}{c|}{ Description } \\
\hline Version 1 & 26 & Positive benevolence + Positive competence + Positive Integrity \\
\hline Version 2 & 31 & Negative benevolence + Positive competence + Positive Integrity \\
\hline Version 3 & 27 & Positive benevolence + Negative competence + Positive Integrity \\
\hline Version 4 & 23 & Negative benevolence + Negative competence + Positive Integrity \\
\hline Version 5 & 29 & Positive benevolence + Positive competence + Negative Integrity \\
\hline Version 6 & 31 & Negative benevolence + Positive competence + Negative Integrity \\
\hline Version 7 & 36 & Positive benevolence + Negative competence + Negative Integrity \\
\hline Version 8 & 31 & Negative benevolence + Negative competence + Negative Integrity \\
\hline Total & 234 & - \\
\hline
\end{tabular}

consequently were fabricated, the information being used was still real. Therefore, it was important to know whether our participants had any experience of transacting with ShopTronics before. As such, the participants were intentionally asked about their familiarity with the seller. Around $97.2 \%$ of the participants claimed that they had never transacted with ShopTronics before, which work as we expected that most of the participants had little information other than the reviews about the seller. In other words, the reviews exposed in the experiment are the only source of information for them to get to know the seller.

\section{Measurement Validation}

SmartPLS ${ }^{1}$ was used for measurement validation and testing the structure model. The descriptive statistics for the study are presented in Table 6. Composite reliabilities of all principal constructs are considered adequate since they exceed 0.8 . Convergent and discriminant validity are tested as follows (Pavlou, et al., 2007): 1) all AVEs in Table 6 are greater than 0.50, suggesting that the variance explained by constructs are much higher than error variance; 2 ) the square root of AVEs are larger than the cross-correlations of the constructs; 3 ) all the cross-correlations of the constructs are lower than 0.90 , which means the constructs are distinct from each other. Also, the cross-loading matrix (as shown in Table 7) suggests adequate convergent and discriminant validity.

One point needing mention is the inter-construct correlation of Benevolence and Integrity, which is 0.746 as shown in Table 6. Although this value looks large, we still think it is acceptable for the following three reasons: 1 ) the value itself is lower than the threshold value of $0.9 ; 2$ ) it is less than the square root of the AVEs of Benevolence $(\sqrt{0.878}=0.937)$ and Integrity $(\sqrt{0.746}=0.863)$; and 3) the obvious difference between the cross-loadings on the target construct and non-target construct indicates that the distinction between these two constructs is still clear, although their interconstruct correlation is comparatively higher than the others. Overall, there is no problem with the reliability and validities of the measurement instruments.

\section{DATA ANALYSIS}

Although the results of the content analysis clearly reveal trust feelings in the manipulated seller reviews in terms of trust antecedents, we intentionally put one more question in the survey, asking the participants their overall trust feeling toward the seller. We then: 1) implemented a structural model to measure how the three antecedents constitute the overall trust, and 2) conducted several factorial analyses to gauge how the reviews impact their readers' trust. 
Table 5. Demographic statistics of the participants

\begin{tabular}{|l|l|l|l|l|}
\hline & \multicolumn{1}{|c|}{$\begin{array}{c}\text { Number of } \\
\text { Responses }\end{array}$} & Frequency (\%) & \multicolumn{1}{c|}{$\begin{array}{c}\text { Accumulated } \\
\text { Frequency (\%) }\end{array}$} \\
\hline \multirow{3}{*}{$\begin{array}{l}\text { Traded with } \\
\text { ShopTronics on } \\
\text { Amazon before? }\end{array}$} & Yes & 7 & 3 & 3 \\
\cline { 2 - 5 } & No & 226 & 96.6 & 99.6 \\
\cline { 2 - 5 } & Missing & 1 & 0.4 & 100 \\
\hline \multirow{4}{*}{$\begin{array}{l}\text { The Frequency of } \\
\text { Online Shopping Last }\end{array}$} & Never & 21 & 9.0 & 9.0 \\
\cline { 2 - 5 } & $1 \sim 5$ & 109 & 46.6 & 55.6 \\
\cline { 2 - 5 } & $11 \sim 20$ & 48 & 20.5 & 76.1 \\
\cline { 2 - 5 } & More than20 & 21 & 13.7 & 89.7 \\
\hline \multirow{4}{*}{ Gender } & Male & 143 & 10.3 & 100 \\
\cline { 2 - 6 } & Female & 90 & 61.1 & 61.1 \\
\cline { 2 - 5 } & Missing & 1 & 38.5 & 99.6 \\
\hline
\end{tabular}

Table 6. Descriptive statistics, correlations and AVE

\begin{tabular}{|l|l|l|l|l|l|l|l|l|}
\hline \multicolumn{1}{|c|}{ Constructs } & Mean (STD) & $\begin{array}{l}\text { Composite } \\
\text { Reliability }\end{array}$ & \multicolumn{1}{|c|}{$\mathbf{1}$} & $\mathbf{2}$ & $\mathbf{3}$ & $\mathbf{4}$ & $\mathbf{5}$ & $\mathbf{6}$ \\
\hline 1. Benevolence & $2.837(1.308)$ & 0.956 & 0.878 & & & & & \\
\hline 2. Competence & $3.000(1.234)$ & 0.947 & 0.418 & 0.855 & & & & \\
\hline 3. Integrity & $2.600(1.221)$ & 0.943 & 0.746 & 0.000 & 0.846 & & & \\
\hline 4. Information Asymmetry & $3.625(1.052)$ & 0.864 & 0.000 & 0.000 & 0.000 & 0.680 & & \\
\hline 5. Seller Opportunism & $3.533(1.095)$ & 0.892 & -0.475 & -0.385 & -0.565 & 0.056 & 0.734 & \\
\hline 6. Uncertainty & $3.923(0.946)$ & 0.930 & -0.349 & 0.000 & -0.429 & 0.170 & 0.000 & 0.816 \\
\hline
\end{tabular}

Note: all the values on the diagonal of the correlation matrix represent AVE (Average Variance Extracted).

\section{Manipulation Check on the Effects of Reviews}

Several factorial analyses were performed to check for the manipulation effect of reviews on trust formation. First, an ANCOVA was applied to the overall trust based on the three factors of benevolence, competence, and integrity. As indicated in Table 8, there is no three-way interaction effect among these three factors $(\mathrm{F}=1.121$, df $1=1, \mathrm{df} 2=210, \mathrm{p}=0.291)$ and no two-way interaction effect between Benevolence and Integrity $(F=2.107, \mathrm{df} 1=1, \mathrm{df} 2=210, \mathrm{p}=0.148)$. However, there are two-way interaction effects between Benevolence*Competence and Competence*Integrity. All of the main effects related to these three antecedents are also significant. All these further indicate that Integrity is distinct from Benevolence. To take a deeper look, we conducted several MANOVAs on each antecedent. Results reveal that the reviews on all three antecedents of trust work as intended, which means that when the reviews contain negative information about either sellers' benevolence, competence or integrity, readers will correspondingly perceive a negative feeling and vice versa.

\section{Testing the Effect of Trust}

As illustrated in Figure 2, the loadings of the instruments on the three antecedents of trust further indicate a good convergent validity of the measurement in the study. As mentioned earlier, the overall 
Table 7. Cross loading matrix

\begin{tabular}{|c|c|c|c|c|c|c|}
\hline & Benevolence & Competence & Integrity & Asymmetry & Opportunism & Uncertainty \\
\hline Asym_1 & 0.0527 & 0.1587 & 0.0243 & 0.783 & -0.0588 & 0.0961 \\
\hline Asym_2 & -0.0404 & 0.0113 & -0.0661 & 0.8603 & 0.1265 & 0.2065 \\
\hline Asym_3 & -0.0022 & 0.1058 & -0.0167 & 0.8289 & 0.0643 & 0.1087 \\
\hline Oppo_1 & -0.3187 & -0.3125 & -0.3611 & 0.0324 & 0.8406 & 0.436 \\
\hline Oppo_2 & -0.2993 & -0.3336 & -0.4044 & 0.0154 & 0.8643 & 0.4335 \\
\hline Oppo_3 & -0.5546 & -0.3414 & -0.6373 & 0.0843 & 0.8657 & 0.4892 \\
\hline Per_Bele_1 & 0.9362 & 0.4144 & 0.7791 & -0.0126 & -0.4666 & -0.3742 \\
\hline Per_Bele_2 & 0.9542 & 0.4125 & 0.7322 & 0.0044 & -0.4591 & -0.3059 \\
\hline Per_Bele_3 & 0.9203 & 0.3424 & 0.7642 & 0.0177 & -0.4036 & -0.2978 \\
\hline Per_Comp_1 & 0.4136 & 0.9156 & 0.4628 & 0.1261 & -0.3357 & -0.2668 \\
\hline Per_Comp_2 & 0.3557 & 0.9212 & 0.3998 & 0.0698 & -0.342 & -0.2785 \\
\hline Per_Comp_3 & 0.3896 & 0.9371 & 0.4456 & 0.1024 & -0.3875 & -0.3376 \\
\hline Per_Inte_1 & 0.7145 & 0.4589 & 0.9217 & -0.1109 & -0.5397 & -0.4182 \\
\hline Per_Inte_2 & 0.7185 & 0.4298 & 0.9352 & -0.0187 & -0.528 & -0.422 \\
\hline Per_Inte_3 & 0.7051 & 0.4117 & 0.9016 & 0.0693 & -0.4892 & -0.3385 \\
\hline Unce_1 & -0.333 & -0.292 & -0.4079 & 0.1566 & 0.4708 & 0.9151 \\
\hline Unce_2 & -0.3642 & -0.2769 & -0.4218 & 0.2014 & 0.4598 & 0.9262 \\
\hline Unce_3 & -0.2513 & -0.2976 & -0.3342 & 0.1039 & 0.5089 & 0.868 \\
\hline
\end{tabular}

trust feeling is only measured by one question: "to which extent do you think this seller is trustworthy?" The three antecedents of trust have significant path coefficients and explain $71.2 \%$ of the variation in the instrument of overall trust. In our context of seller reviews, not all the antecedents are equally important in forming a trust. The magnitude of the standardized path coefficients shows that perceived integrity has the strongest impact (0.604), perceived benevolence is the second $(0.227)$, and perceived competence is the least (0.074). This also indicates that, although perceived benevolence and integrity are highly correlated, they are still distinct from each other.

\section{Testing the Structural Model Relating Trust to Risk and Uncertainty}

The structural model of interest in the study relating trust in sellers to risk and uncertainty (Figure 1) was tested next. The results as illustrated in Figure 3 indicate that both perceived information asymmetry (significant at 0.10 ) and the fears of seller opportunism (significant at 0.10 ) are good predictors of perceived uncertainty, explaining around $30 \%$ of the variability of perceived uncertainty. However, based on the magnitude of the standardized path coefficients, fear of seller opportunism $(0.524)$ has a stronger impact on perceived uncertainty than perceived asymmetry $(0.141)$, suggesting that, in the context of seller reviews, consumers worry more about the possibility of sellers' hidden actions than hidden information. As for the impact of the trust from prior consumers, the model indicates that the trust feeling embedded in the seller reviews has little impact on people's concern about potential hidden information for the following two reasons: 1) none of the paths from the antecedents of trust to perceived information asymmetry is significant; 2) the variance of perceived information asymmetry explained by the trust is very low, around $2.1 \%$. In contrast, the impact of the trust in seller reviews on consumers' fears of seller opportunism is very obvious. First, the paths from perceived competence $(-0.153)$ and perceived integrity $(-0.512)$ to the fears of seller opportunism 
Table 8. Tests of between-subjects effects on trust

\begin{tabular}{|c|c|c|c|c|c|}
\hline Source & $\begin{array}{c}\text { Type III } \\
\text { Sum of } \\
\text { Squares }\end{array}$ & d.f. & $\begin{array}{c}\text { Mean } \\
\text { Square }\end{array}$ & $\mathbf{F}$ & Sig. \\
\hline Corrected Model & $128.304^{\mathrm{a}}$ & 7 & 18.329 & 22.907 & .000 \\
\hline Intercept & 1358.318 & 1 & 1358.318 & 1637.544 & .000 \\
\hline Benevolence & 100.117 & 1 & 100.117 & 120.697 & .000 \\
\hline Competence & 10.842 & 1 & 10.842 & 13.070 & .000 \\
\hline Integrity & 4.163 & 1 & 4.163 & 5.018 & .026 \\
\hline Benevolence ${ }^{*}$ Competence & 16.481 & 1 & 16.481 & 19.869 & .000 \\
\hline Benevolence*Integrity & 1.748 & 1 & 1.748 & 2.107 & .148 \\
\hline Competence $*$ Integrity & 3.720 & 1 & 3.720 & 4.485 & .035 \\
\hline Benevolence ${ }^{*}$ Competence $*$ Integrity & .930 & 1 & .930 & 1.121 & .291 \\
\hline Error & 174.192 & 210 & .829 & & \\
\hline Total & 1670.000 & 218 & & & \\
\hline Corrected Total & 302.495 & 217 & & & \\
\hline
\end{tabular}

a. $\mathrm{R}$ Squared $=.424$ (Adjusted R Squared $=.405)$

Figure 2. The structural model on trust

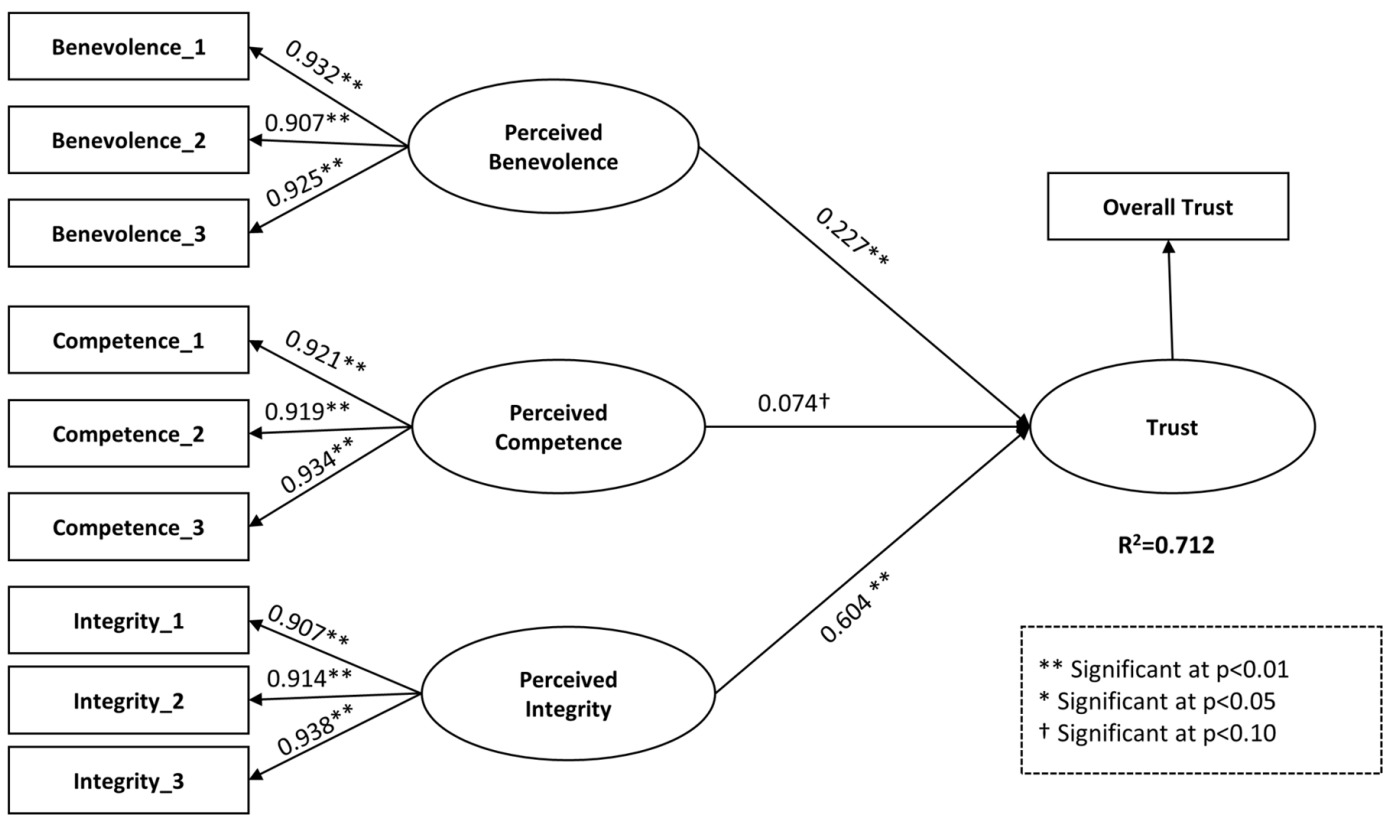

are significant at 0.01 . Second, these three antecedents of trust can explain $33.8 \%$ of the variance in the fears of seller opportunism. The standardized path coefficients further suggest that only the information on sellers' integrity and competence, especially integrity, in the seller reviews has the ability to lessen consumers' concerns on sellers' potential hidden actions. Consumers do not appear 
Figure 3. Coefficients and R Squares for the research model

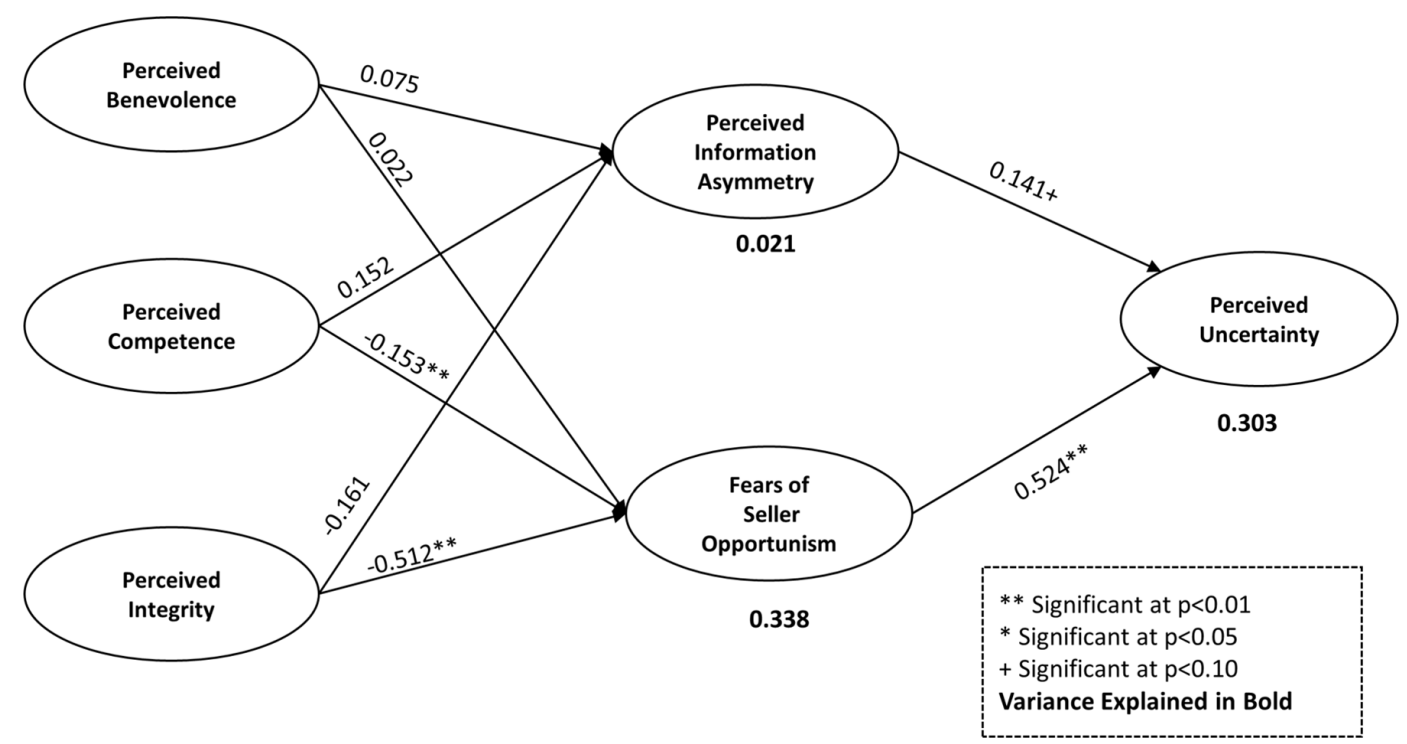

to care about sellers' benevolence, although they can differentiate the change in the content regarding benevolence as suggested by earlier findings.

To further test the relative lack of importance of perceived information asymmetry, a simplified model was run after removing perceived information asymmetry from the full model. The standardized path coefficients for testing the simplified structural model are presented in Figure 4. Consistent with the findings above, only the paths from perceived integrity $(-0.154)$ and competence $(-0.512)$ to perceived risks are significant. The change in the R2 of perceived uncertainty is relatively small, only decreasing by $6.27 \%$. All these suggest that the fears of information asymmetry are not a big concern in the context of seller reviews, and the information reflecting sellers' benevolence cannot help mitigate consumers' concerns on either information asymmetry or seller opportunism.

The effects of control variables and the mediation effect of perceived seller opportunism were tested on the simplified model. Two modified models were consequently created. In the model to test the effects of control variables, new links were drawn respectively from the control variables (including online shopping experience, gender, and household incomes) to both perceived seller opportunism and perceived uncertainty. It turns out that two links became significant: 1) the link from household incomes to perceived seller opportunism has become significant (-0.132) at 0.05, and 2) the link from online shopping experience to perceived uncertainty has become barely significant (-0.096) at 0.10 . All other newly-added links remained insignificant. If the values of $\mathrm{R}^{2}$ are also considered, we believe the effects of the control variables remain negligible, because both $\mathrm{R}^{2}$ pertaining to the two perceptions were barely increased by 0.01 .

In the second model, the mediation effect of perceived seller opportunism was tested by examining both the direct and indirect effects of the three trust antecedents. This test was conducted in two steps: 1) we added three direct links from the antecedents of trust to perceived uncertainty; 2) we removed the construct of perceived seller opportunism from the model. It turns out that, without the presence of perceived seller opportunism, all the direct links from the trust antecedents to perceived uncertainty were significant at 0.05 . However, if the construct of the perceived seller opportunism was added back into the model, all the direct links became insignificant. All the evidence suggests a good mediation effect of the perceived seller opportunism (Liang, Nilesh, Hu, \& Xue, 2007).

Overall, the tests on the structural model suggest that only the hypotheses of H4, H6, H7 and H8 are supported by this study. 
Figure 4. Coefficients and R Squares for the simplified model

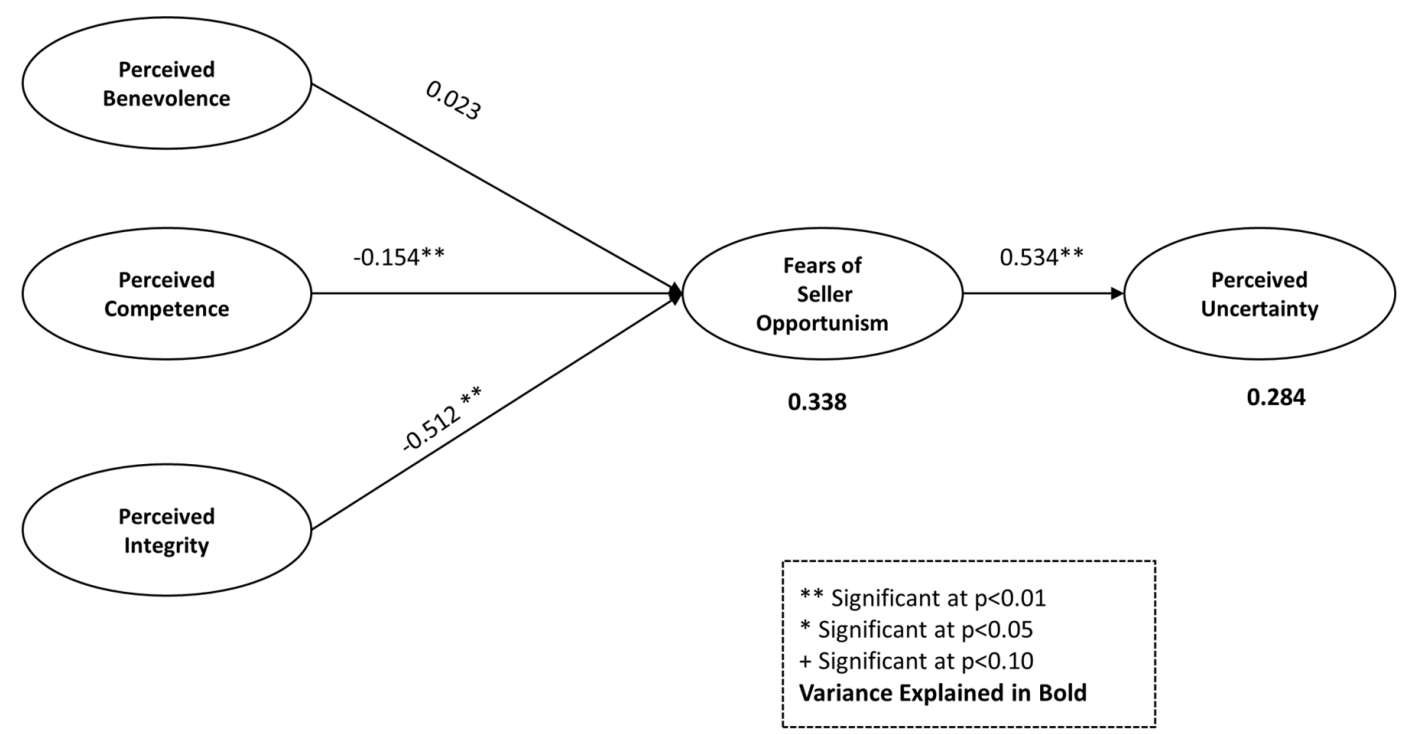

\section{DISCUSSION}

This study measured the effect of seller reviews on perceived uncertainty in e-commerce transactions from the trust perspective. There are several expected findings as well as several unexpected ones. The risks in online transactions were measured in the format of information asymmetry (hidden information) and seller opportunism (hidden actions) based on the principal-agent theory. In line with the theory, the uncertainty in online transactions is significantly comprised of concerns about the seller's potential hidden information and hidden actions. However, compared to seller opportunism, the concern on information asymmetry is negligible, which is understandable. With the easy access to the internet, there is very little about the products they do not know, so hidden information appears to be less of a concern. On the contrary, consumers worry more about the performance of the sellers.

The study additionally shows that, although readers can correctly sense the feelings of benevolence and competence in the reviews, the information on benevolence does not affect readers' perceptions of either risks or uncertainty at all. As for integrity, readers' perception does not change regardless of whether the content of the information on sellers' integrity is positive or negative. The path coefficients in the structural model confirms this finding. Compared to perceived competence, perceived integrity has a much stronger effect on lessening perceived risk. A MANOVA additionally shows that to differentiate sellers' integrity based on seller reviews, we should simultaneously consider sellers' competence.

The findings in this study have implications for both theory and practice. First, while trust has been extensively discussed as an important factor in online transactions, our study successfully linked traditional models of trust with consumer reviews. In addition, our study suggests that the three antecedents of trust are not equally important. This brings up the question: 'Should we differentiate the antecedents of trust contextually?' That is, should the trust be measured with a different focus on the antecedents in accordance with context?

Second, this study confirms that the principal-agent theory is a valid lens for the study of the impact of seller reviews on uncertainty. Both the concerns on hidden information and hidden actions are important factors in shaping the uncertainty in online transactions, however, the study indicates that the trust feeling in seller reviews impacts the uncertainty only through consumers' concerns on sellers' hidden actions but not hidden information. 
The study has obvious practical implications for practitioners as well. First, the findings in content analysis reveal the major issues in online transactions which produce satisfied or dissatisfied consumers, for instance, shipping, product quality, additional charges for shipping and refunding, communication and so forth. The weights of the semantic terms additionally reveal that, out of all the concerns, shipping is the most important concern, the convenience of refunding is the second, product quality is the third, the speed of transacting is the fourth, and the ease of communicating with sellers is the fifth. In some web portals such as eBay, an additional chance to rate sellers' performance based on the items - such as products, communication, shipping, and the charges on shipping and handling - is offered. Our findings show that it is reasonable to design the questionnaire in this way, but there is still plenty of room to improve the rating system. For instance, weights should be assigned to the questions in the survey, because it would be more realistic to reflect sellers' performance in transactions when calculating the overall score for each seller and rank those sellers on the basis of these scores.

Second, the findings in the behavioral study point to an efficient way to read the tone in seller reviews especially for web designers. From the perspective of risk reduction, web designers should collect more information on seller's competence and integrity, rather than benevolence. It is common nowadays for web portals such as Amazon to provide a summary of the content in reviews on the top of review sessions. In addition to the statistical summary of ratings, our study demonstrates that the content of reviews also impacts consumers' decision making. To improve the efficiency of information sharing in seller reviews, web designers should retrieve more information on sellers' integrity and competence from seller reviews and put them on the top. The performance of sellers can additionally be assessed on their integrity and competence, supplementing to the rating system. This dual process of assessment can strengthen the accuracy of predicting sellers' performance and simplify the procedure of identifying the untrustworthy sellers in e-markets.

There are some limitations to the study. First, the reviews of interest in this study are those of sellers. The findings in this study cannot be generalized to the reviews on products. Product reviews differ from seller review not only in length but also in the content. Product reviews are normally much longer than seller reviews and cover more aspects of the transaction, from the quality of products to after-sale service. Consequently, the measure of the effect of product reviews would be more comprehensive.

Second, while we investigated the risks related to hidden information and hidden actions as indicated by the principal-agent theory, there are many other risks in online transactions worth checking. The explained variance of perceived uncertainty in this study is $30 \%$, suggesting that there is still plenty of room to consider other factors. As discussed earlier, the risks can also be measured in the format of financial loss, time loss, performance loss, social loss, and psychological loss. Although there is no direct evidence that these risks are associated with seller reviews, it may be worthy of further investigation.

Third, with respect to the content analysis in the study, the number of reviews were small, making it possible to cluster the semantic terms manually. However, if the number of reviews is enormous, an automatic process to classify reviews may be needed. 


\section{REFERENCES}

Ahmad, S. N., \& Laroche, M. (2015). How do expressed emotions affect the helpfulness of a product review? Evidence from reviews using latent semantic analysis. International Journal of Electronic Commerce, 20(1), 76-111. doi:10.1080/10864415.2016.1061471

Awad, N. F., \& Ragowsky, A. (2008). Establishing trust in electronic commerce through online word of mouth: An examination across genders. Journal of Management Information Systems, 24(4), 101-121. doi:10.2753/ MIS0742-1222240404

Bergen, M., Dutta, S., \& Walker, O. C. Jr. (1992). Agency relationships in marketing: A review of the implications and applications of agency and related theories. Journal of Marketing, 56(3), 1-24. doi:10.1177/002224299205600301

Cheung, C. M. K., \& Lee, M. K. O. (2008). Online Consumer Reviews: Does Negative Electronic Word-ofMouth Hurt More? Paper presented at the AMCIS 2008 Proceedings.

Chevalier, J. A., \& Mayzlin, D. (2006). The effect of word of mouth on sales: Online book reviews. JMR, Journal of Marketing Research, 43(3), 345-354. doi:10.1509/jmkr.43.3.345

Clemons, E. K., Gao, G. G., \& Hitt, L. M. (2006). When online reviews meet hyperdifferentiation: A study of the craft beer industry. Journal of Management Information Systems, 23(2), 149-171. doi:10.2753/MIS07421222230207

Delen, D., \& Crossland, M. D. (2008). Seeding the survey and analysis of research literature with text mining. Expert Systems with Applications, 34(3), 1707-1720. doi:10.1016/j.eswa.2007.01.035

Fang, H., Guo, G., \& Zhang, J. (2015). Multi-faceted trust and distrust prediction for recommender systems. Decision Support Systems, 71, 37-47. doi:10.1016/j.dss.2015.01.005

Gefen, D., Karahanna, E., \& Straub, D. W. (2003). Trust and TAM in online shopping: An integrated model. Management Information Systems Quarterly, 27(1), 51-90. doi:10.2307/30036519

Ghose, A., \& Ipeirotis, P. G. (2010). Estimating the helpfulness and economic impact of product reviews: Mining text and reviewer characteristics. IEEE Transactions on Knowledge and Data Engineering, 23(10), 1498-1512. doi:10.1109/TKDE.2010.188

Hu, N., Liu, L., \& Zhang, J. (2008). Do online reviews affect product sales? The role of reviewer characteristics and temporal effects. Information Technology Management, 9(3), 201-214. doi:10.1007/s10799-008-0041-2

Jiang, B.-J., \& Wang, B. (2008). Impact of Consumer Reviews and Rating on Sale, Price, and Profits: Theory and Evidence. Paper presented at the 29th ICIS, Paris.

Kim, D. J., Ferrin, D. L., \& Rao, H. R. (2008). A trust-based consumer decision-making model in electronic commerce: The role of trust, perceived risk, and their antecedents. Decision Support Systems, 44(2), 544-564. doi:10.1016/j.dss.2007.07.001

Liang, H., Nilesh, S., Hu, Q., \& Xue, Y. (2007). Assimilation of enterprise systems: The effect of institutional pressures and the mediating role of top management. Management Information Systems Quarterly, 31(1), 59-87. doi: $10.2307 / 25148781$

Lim, K. H., Sia, C. L., Lee, M. K. O., \& Benbasat, I. (2006). Do I trust you online, and if so, will I buy? An empirical study of two trust-building strategies. Journal of Management Information Systems, 23(2), 233-266. doi:10.2753/MIS0742-1222230210

McKnight, D. H., \& Chervany, N. L. (2001). What trust means in e-commerce customer relationships: An interdisciplinary conceptual typology. International Journal of Electronic Commerce, 6(2), 35-59. doi:10.108 0/10864415.2001.11044235

McKnight, D. H., Choudhury, V., \& Kacmar, C. (2002). Developing and validating trust measures for e-commerce: An integrative typology. Information Systems Research, 13(3), 334-359. doi:10.1287/isre.13.3.334.81

Mishra, D. P., Heide, J. B., \& Cort, S. G. (1998). Information Asymmetry and Levels of Agency Relationships. JMR, Journal of Marketing Research, 35(3), 277-295. doi:10.1177/002224379803500301 
Mudambi, S. M., \& Schuff, D. (2010). What Makes A Helpful Online Review? A Study Of Customer Reviews On Amazon.com. Management Information Systems Quarterly, 34(1), 185-200. doi:10.2307/20721420

Ong, T., Mannino, M., \& Gregg, D. (2014). Linguistic Characteristics of Shill Reviews. Electronic Commerce Research and Applications, 13(2), 69-78. doi:10.1016/j.elerap.2013.10.002

Pavlou, P. A., \& Dimoka, A. (2006). The Nature and Role of Feedback Text Comments in Online Marketplaces: Implications for Trust Building, Price Premiums, and Seller Differentiation. Information Systems Research, 17(4), 392-414. doi:10.1287/isre.1060.0106

Pavlou, P. A., Huigang, L., \& Yajiong, X. (2007). Understanding and Mitigating Uncertainty In Online Exchange Relationship: A Principal-agent Perspective. Management Information Systems Quarterly, 31(1), 105-136. doi: $10.2307 / 25148783$

Porter, M. F. (1980). An Algorithm for Suffix Stripping. Program, 14(3), 130-137. doi:10.1108/eb046814

Rouibah, K., Lowry, P. B., \& Hwang, Y. (2016). The Effects of Perceived Enjoyment and Perceived Risks on Trust Formation and Intentions to Use Online Payment Systems: New Perspectives from An Arab Country. Electronic Commerce Research and Applications, 19, 33-43. doi:10.1016/j.elerap.2016.07.001

Singh, J., \& Sirdeshmukh, D. (2000). Agency and Trust Mechanisms in Consumer Satisfaction and Loyalty Judgments. Journal of the Academy of Marketing Science, 28(1), 150-167. doi:10.1177/0092070300281014

Sparks, B. A., Perkins, H. E., \& Buckley, R. (2013). Online Travel Reviews as Persuasive Communication: The Effects of Content Type, Source, and Certification Logos on Consumer Behavior. Tourism Management, 39, 1-9. doi:10.1016/j.tourman.2013.03.007

Tian, F., Wu, F., Chao, K.-M., Zheng, Q., Shah, N., Lan, T., \& Yue, J. (2016). A Topic Sentence-based Instance Transfer Method for Imbalanced Sentiment Classification of Chinese Product Reviews. Electronic Commerce Research and Applications, 16, 66-76. doi:10.1016/j.elerap.2015.10.003

Utz, S., Kerkhof, P., \& van den Bos, J. (2012). Consumers Rule: How Consumer Reviews Influence Perceived Trustworthiness of Online Stores. Electronic Commerce Research and Applications, 11(1), 49-58. doi:10.1016/j. elerap.2011.07.010

Wang, W., Qiu, L., Kim, D., \& Benbasat, I. (2016). Effects of Rational and Social Appeals of Online Recommendation Agents on Cognition- and Affect-based Trust. Decision Support Systems, 86, 48-60. doi:10.1016/j.dss.2016.03.007

Weiss, S. M. (2005). Text Mining: Predictive Methods for Analyzing Unstructured Information. New York: SpringerLink (Online service). doi:10.1007/978-0-387-34555-0

Zhan, J., Loh, H. T., \& Liu, Y. (2009). Gather Customer Concerns from Online Product Reviews - A Text Summarization Approach. Expert Systems with Applications, 36(2, Part 1), 2107-2115. doi:10.1016/j. eswa.2007.12.039

Zhu, F., \& Zhang, X. (2010). Impact of Online Consumer Reviews on Sales: The Moderating Role of Product and Consumer Characteristics. Journal of Marketing, 74(2), 133-148. doi:10.1509/jm.74.2.133

\section{ENDNOTE}

Ringle, C.M./Wende, S./Will, S.: SmartPLS 2.0 (M3) Beta, Hamburg 2005, http://www.smartpls.de 


\section{APPENDIX 1}

Table 9. Measurement items for principal constructs

\begin{tabular}{|c|c|c|}
\hline $\begin{array}{l}\text { Principal } \\
\text { Construct }\end{array}$ & Measurement Items (1-5 Likert Scale) & Reference \\
\hline Trust & $\begin{array}{l}\text { - I expect that the vendor has good intentions toward me. (Benevolence) } \\
\text { - I believe that the vendor would act in my best interest. (Benevolence) } \\
\text { - If I required help, the vendor would do it best to help me. (Benevolence) } \\
\text { - The vendor is competent and effective in selling products online. (Competence) } \\
\text { - The vendor performs its role of selling products very well. (Competence) } \\
\text { - Overall, this vendor is a capable and proficient online product seller. (Competence) } \\
\text { - Promises made by the vendor are likely to be reliable. (Integrity) } \\
\text { - I would characterize this vendor as honest. (Integrity) } \\
\text { - I expect that the vendor keeps its commitments. (Integrity) }\end{array}$ & $\begin{array}{l}\text { (McKnight, } \\
\text { Choudhury et al., } \\
\text { 2002; Pavlou, } \\
\text { Huigang et al., } \\
\text { 2007) }\end{array}$ \\
\hline $\begin{array}{l}\text { Fears of Seller } \\
\text { Opportunism }\end{array}$ & $\begin{array}{l}\text { - Given a chance, the vendor might send me a counterfeit product. } \\
\text { - Given a chance, the vendor might send me a product of low quality. } \\
\text { - Given a chance, the vendor might breach formal or informal agreements to their or its benefit. }\end{array}$ & $\begin{array}{l}\text { (Pavlou, Huigang } \\
\text { et al., 2007) }\end{array}$ \\
\hline $\begin{array}{l}\text { Perceived } \\
\text { Information } \\
\text { Asymmetry }\end{array}$ & $\begin{array}{l}\text { - The vendor has more information about the quality of their product than I do. } \\
\text { - The vendor has more information about how my product order will be handled than I do. } \\
\text { - The vendor has more information about their/its selling practices than I do. }\end{array}$ & $\begin{array}{l}\text { (Pavlou, Huigang } \\
\text { et al., 2007) }\end{array}$ \\
\hline $\begin{array}{l}\text { Perceived } \\
\text { Uncertainty }\end{array}$ & $\begin{array}{l}\text { - I feel that purchasing the product from the vendor involves a high degree of uncertainty. } \\
\text { - I feel that the uncertainty associated with purchasing the product from the vendor is high. } \\
\text { - There is a high degree of product uncertainty (i.e. the product you receive may not be exactly what you } \\
\text { want) when purchasing the product from the vendor. }\end{array}$ & $\begin{array}{l}\text { (Pavlou, Huigang } \\
\text { et al., 2007) }\end{array}$ \\
\hline
\end{tabular}

Jing Yang is an Assistant Professor of Management Information Systems in the School of Economics and Business, the State University of New York at Oneonta. She received her Ph. D. from Oklahoma State University, Stillwater. She has published several refereed journal and conference articles in AMCIS, DSI, IGI Global, Nankai Business Review International, Decision Support Systems and so on. Her current research interests include consumer behaviour in e-commerce, information security, and business analytics.

Rathindra Sarathy is the Ardmore Chair in Business Administration in the Department of Management Science of Information Systems in the Spears School of Business at Oklahoma State University. He received his Ph.D. from Texas A\&M University. He has published in many journals including ACM Transactions on Database Systems, Decision Sciences, Decision Support Systems, Information Systems Research, Information Systems Journal, Journal of Database Management, Management Science, and Operations Research. His current research interests include privacy and confidentiality, data masking, data and information security, e-commerce and behavioral modeling.

Tao Wu is currently a lecturer of Computer Science in the Department of Math, Computer Science, and Statistics, the State University of New York at Oneonta. He received his Ph.D. from Oklahoma State University, Stillwater. His current research interests include information science and data science. 